\title{
Sustaining Mature Thermal Protection Systems Crucial for Future In-Situ Planetary Missions
}

\author{
E. Venkatapathy ${ }^{1}$, J. Feldman ${ }^{1}$, \\ D. S. Adams ${ }^{9}$, R. Beck ${ }^{1}$, D. Ellerby ${ }^{1}$, M. Gasch ${ }^{1}$, H. Hwang ${ }^{1}$, \\ A. Ingersoll ${ }^{16}$, and M. Stackpoole ${ }^{1}$
}

Endorsers (70):

Alunni, A., ${ }^{1}$ Amato, M., ${ }^{3}$ Arnold., J., ${ }^{1}$ Arteya, S., ${ }^{10}$ Atkinson, D., ${ }^{8}$ Austin, A., ${ }^{8}$ Barnhardt, M., ${ }^{1}$ Beauchump, P., ${ }^{8}$ Bienstock, B., ${ }^{8}$ Bouslog, S., ${ }^{5}$ Brandis, A., ${ }^{1}$ Calamino, A., ${ }^{7}$ C assell, A., ${ }^{1}$ ChavezGarcia, J., ${ }^{1}$ Cheatwood, N., ${ }^{2}$ Dweyer Cianciolo, A., ${ }^{2}$ Cuzzi, J., ${ }^{1}$ Dillman, R., ${ }^{2}$ Driver, D., ${ }^{1}$ Dutta, S., ${ }^{2}$ Edwards, C., ${ }^{8}$ Esposito, L., ${ }^{12}$ Estrada, P., ${ }^{1}$ Fowler, M., ${ }^{5}$ Gage, P., ${ }^{15}$ Gayle, S., ${ }^{2}$ Greg, G., ${ }^{1}$ Hash, D., ${ }^{1}$ Haskins, J., ${ }^{1}$ Hibbard, K., ${ }^{9}$ Hoffman, P., ${ }^{8}$ Hofstadter, M., ${ }^{8}$ Huff, J., ${ }^{4}$ Hughes, K., ${ }^{3}$ Hunter, G., ${ }^{6}$ James, C., ${ }^{8}$ Kazemba, C., ${ }^{1}$ Kontinos, D., ${ }^{1}$ Kremic, T., ${ }^{1}$ Langston, S., ${ }^{1}$ Libben, B., ${ }^{1}$ Lobbia, M., ${ }^{8}$ Mahzari, M., ${ }^{1}$ Martinez, E., ${ }^{1}$ Miller, R., ${ }^{1}$ Milos, F., ${ }^{1}$ Mousis, O., ${ }^{14}$ Munk, M., ${ }^{2}$ Muppidi, S., ${ }^{1}$ Nelessen, A., ${ }^{8}$ Nishioka, O., ${ }^{1}$ Partridge, H., ${ }^{1}$ Peterson, K., ${ }^{1}$ Poteet, C., ${ }^{2}$ Prabhu, D., ${ }^{1}$ Rabinovich, J., ${ }^{8}$ Reh, K., ${ }^{8}$ Rymer, A., ${ }^{9}$ Sayanagi, K., ${ }^{14}$ Splinter, S., ${ }^{2}$ Stern, E., ${ }^{1}$ C. Szalai, Vander Kam, J., ${ }^{1}$ Wercinski, P., ${ }^{1}$ White, T., ${ }^{1}$ Williams, J., ${ }^{1}$ Wright, M., ${ }^{1}$ Wright, H., ${ }^{2}$ Young, Z., ${ }^{1}$ and Zarchi, K. ${ }^{1}$

Affiliations:

${ }^{1}$ NASA ARC, ${ }^{2}$ NASA LaRC, ${ }^{3}$ NASA GSFC, ${ }^{4}$ NASA KSC, 5 NASA JSC, ${ }^{6}$ NASA GRC, ${ }^{7}$ NASA HQ, ${ }^{8} \mathrm{JPL}$, ${ }^{9} \mathrm{APL},{ }^{10}$ Univ. of Michigan, ${ }^{11} \mathrm{AMA}$, Inc., ${ }^{12} \mathrm{CU}$, Boulder, ${ }^{13}$ Laboratory of Astrophysics of Marseille, ${ }^{14}$ Hampton University, ${ }^{15}$ Neerim, Corp., and ${ }^{16}$ CalTech 
Sustaining Mature Thermal Protection Systems Crucial for Future In-Situ Planetary Missions

Abstract: This paper seeks to inform of the need for, and approaches to, sustaining critical thermal protection systems (TPS) for in-situ planetary missions in the coming decade. The key technologies, HEEET and PICA, are needed only for NASA missions. These technology capabilities will most likely atrophy due to uncertain future needs and thus place future science missions at risk. Therefore we advocate for and propose an outline of how NASA can sustain these two TPS technologies in the coming decade for the missions in 2030 and beyond.

Introduction: The technologies discussed herein are needed for the severe entry environments that will be encountered in missions deploying landers, probes, aerial platforms, and for skimmer missions [1]. The challenges for the specially capable TPS are multifaceted: the technology is only needed for NASA in-situ missions, which occur at a low cadence; the raw materials, production processes, or system integration for the technology are unique; and the knowledge and expertise in system manufacturing, design and/or integration lies with a small group of people within NASA and industry whose vital skills will atrophy in the absence of applying the technology. Phenolic Impregnated Carbon Ablator (PICA) and Heatshield for Extreme Entry Environment Technology (HEEET) are NASA-invented technologies essential for in-situ planetary missions for which no alternatives exist. PICA and HEEET are at high technology readiness levels (TRL) and are currently ready for missions [1]. The primary recommendation is for NASA to perform annual need assessments and technology loss risk assessments for these crucial technologies.

NASA has been plagued by TPS obsolescence, which occurs when a unique technology is not needed or produced for a significant amount of time. The immense challenges, expense, and recovery time of Apollo's Avcoat for Orion are well-known to the TPS community [2]. The loss of heritage carbon phenolic (HCP) technology used on NASA's Pioneer-Venus and Galileo missions may have delayed some planetary science missions in the past decade and led directly to NASA's investment in the Heatshield for Extreme Entry Environment Technology (HEEET) project to develop a new 3D woven ablative capability for Venus, Saturn, Uranus, Neptune and higher speed sample return missions $[3,4]$. Some of the challenges associated with sustaining TPS, due to low mission cadence, came into play with the TPS material SLA-561V between the Mars Viking (early 1970's) and Pathfinder missions (early 1990's) [5] and again between the Mars Science Laboratory (MSL) backshell (built in 2008) and the Mars Interior Exploration using Seismic Investigations, Geodesy and Heat Transport heatshield (InSight, built in 2015) missions.

Planetary entry creates severe environments which span orders of magnitude in terms of heat flux and pressure, depending on the specific mission design parameters such as entry velocity, entry flight path angle, size and shape of the entry system, direct or lift guided entry or aerocapture, and destination atmosphere. While peak heat-flux and pressure primarily determine the applicability of any given TPS, the heat-load for any given mission determines the thickness and mass of TPS required to protect the vehicle. A fail-safe and an efficient TPS is what mission designers look for. No single TPS solution works for all mission architectures in this regard. The combined capabilities of PICA (TRL 9 for most missions) and HEEET (TRL 6 for most missions where applicable) cover a wide range of heat fluxes and pressures, as shown in Figure 1. PICA's capability covers a range of heat fluxes from approximately 100 to $2000 \mathrm{~W} / \mathrm{cm}^{2}$ and was/is the heatshield for Stardust, OSIRIS-REx, Mars Science Laboratory (MSL) and Mars 2020. PICA is baselined for Dragonfly, Mars Sample Return's SRL (Sample Retrieval Lander) and the EEV (Earth Entry Vehicle) backshell. HEEET has been tested across many facilities at highest condition 
Sustaining Mature Thermal Protection Systems Crucial for Future In-Situ Planetary Missions

available and it has not shown any failure. HEEET is very capable in the range of $1500 \mathrm{~W} / \mathrm{cm}^{2}$ to at least $<6,000 \mathrm{~W} / \mathrm{cm}^{2}$ and pressures $<6 \mathrm{~atm}$. This was demonstrated via arc jet testing at peak conditions of $3600 \mathrm{~W} / \mathrm{cm}^{2} / 5.5 \mathrm{~atm}$ and $1300 \mathrm{~W} / \mathrm{cm}^{2} / 14 \mathrm{~atm}$, and in laser testing at up to 8000 $\mathrm{W} / \mathrm{cm}^{2}$.

These two systems cover nearly all direct entry, entry from orbit, aerocapture or skimming planetary science missions studied and proposed for the current and future decades. It should be noted that while Avcoat, the Apollo era ablative material, revived and flight tested on Orion EFT-1, could be considered as a TPS capable of supporting some of the planetary missions, the current Artemis-1 mission has a newer formulation of Avcoat, without honeycomb, and is a non-monolithic system yet to be flight proven. In addition, the ablative material performance limit of Avcoat is estimated to be around $1200 \mathrm{~W} / \mathrm{cm}^{2}$, and it is not considered as a viable material for most planetary missions at this time. Hence, alternatives to PICA and HEEET currently do not exist at high TRL for the full range of aeroheating at which their capabilities have been demonstrated.
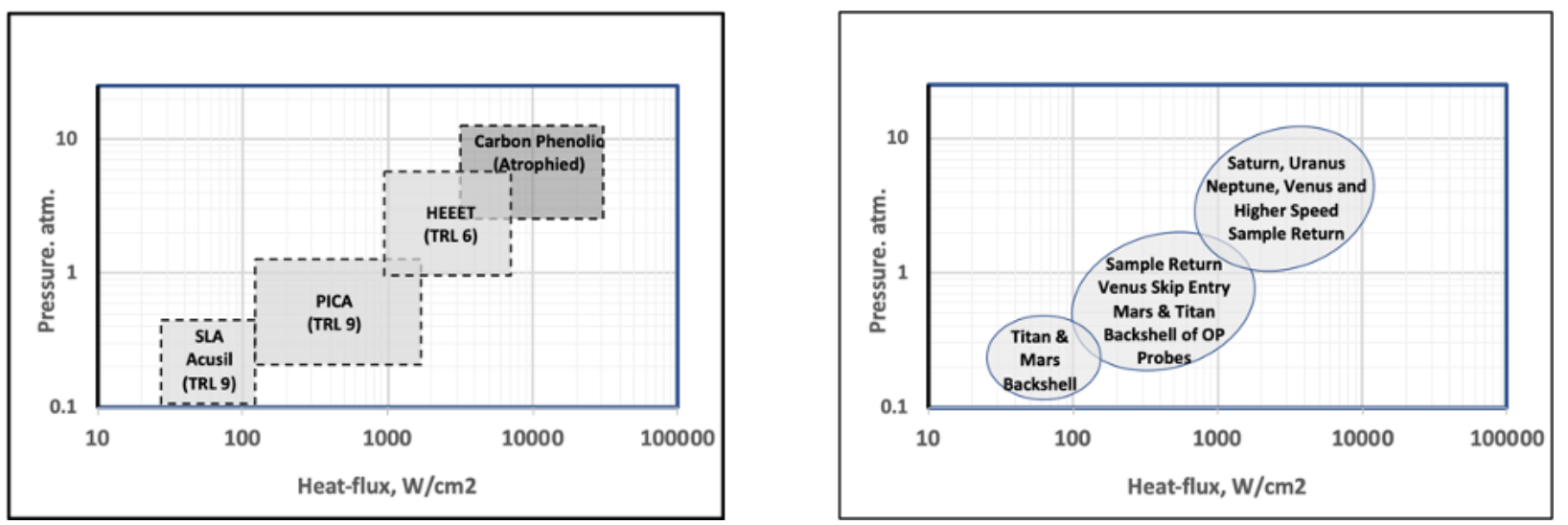

Figure 1. TPS material capabilities and mission environments compared

Since NASA's planetary science missions are competed or designated across a range of funding classes (SIMPLEx, Discovery, New Frontiers, Flagship), mission proposers and planners need to ensure the critical technology is readily available. If critical technologies such as TPS are not readily available, then the proposals will be considered too risky for selection. In order to ensure missions needing thermal protection systems are not unfairly penalized, NASA invested in HEEET and offered it with incentives in the recent New Frontier and Discovery proposal calls as HEEET was matured to TRL 6. NASA also invested in PICA to ensure its availability

Industry-invented ablative materials SLA-561V and Acusil II, with crucial TPS capability for missions below $100 \mathrm{~W} / \mathrm{cm}^{2}$, have been somewhat sustained over many years and flown on multiple Mars missions. Each time a long period has elapsed between missions, SLA-561V manufacturing on large structures has required extensive redevelopment and re-learning. Acusil II, manufactured by Peraton for DOD projects on a recurring basis, has been reliably reproduced for NASA missions requiring RF transparent materials. However, neither SLA-561V nor Acusil II are capable of mid-to-high heatshield entry environments (including those of MSL and Mars 2020). On the other hand, missions that require HEEET for the heatshield are able to use PICA for 
the backshell. Hence PICA and HEEET are enabling across a wide range of in-situ planetary science missions.

In addition to the capabilities discussed above, unique testing infrastructure (such as arc jets and laser facilities) and specialized tools/skills (including aerothermal predictions, TPS material selection and sizing, thermo-structural analysis of complex integrated elements) are also required to enable in-situ planetary missions. Once developed, this expertise in areas of system design, fabrication, integration, and testing of components (from sub-systems to system) is essential. Such expertise resides within NASA and select vendors. Additional key outside vendors include raw materials suppliers, TPS manufacturers and entry vehicle prime contractors. While NASA actively strives to maintain critical capabilities among its field centers, external vendors do not have the same priorities or obligations and do not maintain NASA-critical technology or expertise in the absence of use.

Sustaining Crucial TPS Capability: PICA. PICA is an ablative TPS with a simple composition consisting of a porous chopped carbon fiber preform (FiberForm ${ }^{\mathrm{TM}}$ ) infused with a high-surface area phenolic resin matrix. The phenolic infusion is at a relatively low level of loading such that the final material is highly porous and has a low density. This results in a relatively efficient ablative material. PICA was invented by the NASA Ames Research Center and initially was used for and enabled the Stardust mission. It has since been used for OSIRIS-REX, Mars Science Lab and Mars 2020 heatshields (Figure 2) [6,7]. Fiber Materials Inc. (FMI) was a logical vendor for technology transfer of PICA fabrication, since the substrate for PICA was a commercial FMI product (FiberForm ${ }^{\mathrm{TM}}$ ) sold by $\mathrm{FMI}$ as furnace insulation and FMI had experience working with phenolic resin for other applications.
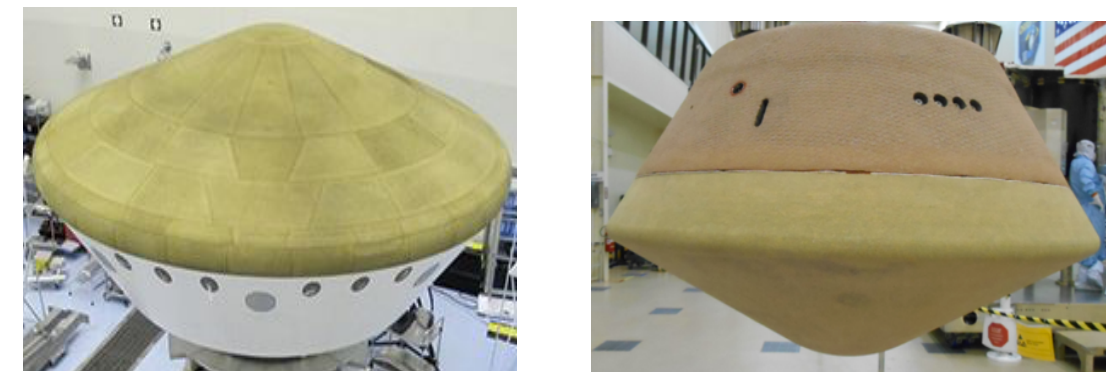

Figure 2. Tiled PICA is used for heatshields over 1.4 meters in diameter such as MSL (left) while single-piece PICA (up to 1.4 meters) was used on OSIRIS-REx (right)

In the last 15 years, the primary source of the rayon precursor to carbon fiber in FiberForm ${ }^{\text {TM }}$ has changed three times. In all cases FMI has been able to successfully accommodate the change into their commercial line while NASA was forced to re-qualify PICA to verify its performance. Most recently, in 2017, FMI switched to a domestically supplied Lyocell fiber when the previous Sniace rayon became unavailable. For PICA, FiberForm ${ }^{\mathrm{TM}}$ is clearly the constituent of greatest sustainability concern. This was somewhat mitigated by the commercial nature of its utilization for furnace insulation. However, in 2019 FMI informed NASA that FiberForm $^{\text {TM }}$ production would cease due to market forces. NASA is currently working with FMI to maintain 
Sustaining Mature Thermal Protection Systems Crucial for Future In-Situ Planetary Missions

FiberForm ${ }^{\mathrm{TM}}$ and PICA production capabilities in support of the Dragonfly mission as well as Mars Sample Return.

\section{PICA Risk Assessment}

- With no FiberForm ${ }^{\mathrm{TM}}$ or PICA manufacture by FMI planned after 2024, production and technical skills will diminish significantly even if specialized equipment and documentation remain in place.

- Reviving manufacturing capability can require years and is often costlier than maintaining it with periodic production (as NASA experienced with Avcoat and assessed to be the case with heritage carbon phenolic).

- NASA ARC Entry Systems and Technology Division has documented detailed PICA fabrication sustainability risks (reference 8 ), and a risk matrix is shown in Figure 3.

\section{Proposed PICA Sustainability Risk Mitigations}

- NASA should perform periodic assessments of future PICA demand, starting material availability, processing equipment status, and FMI technical capabilities related to PICA.

- Periodic assessments should be conducted to determine whether technology atrophy risk has changed, and the PICA assessment document [8] should be updated based on this information.

- If the risk becomes high, NASA ARC, the responsible center, should bring a funding proposal forward to $\mathrm{HQ}$ to mitigate the risk through manufacturing or other means.

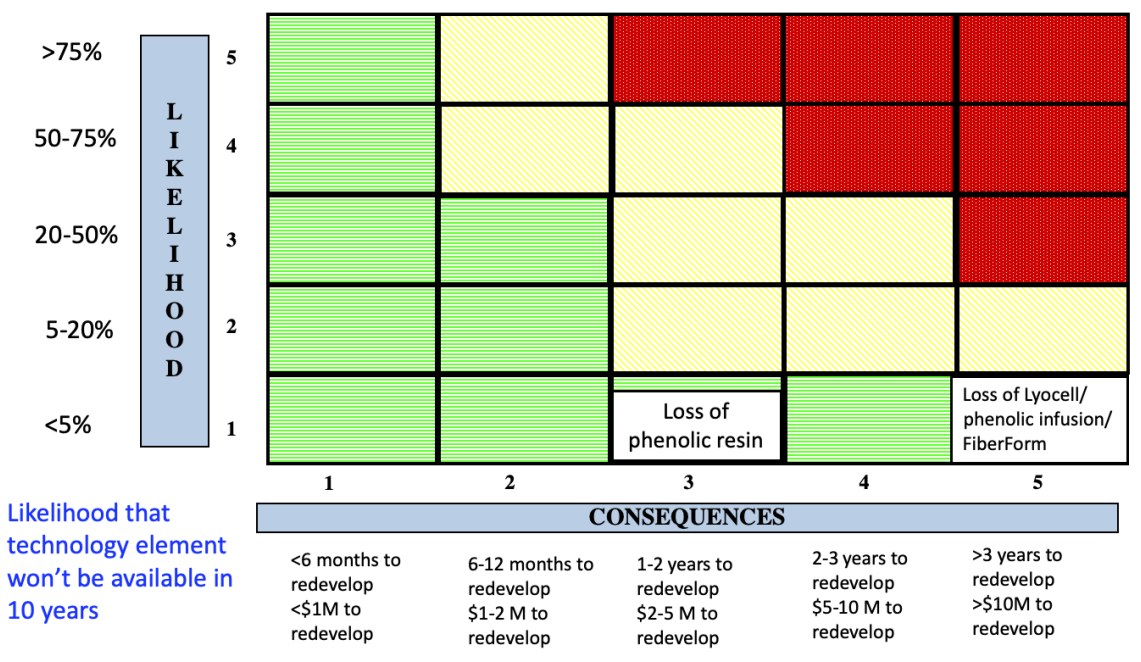

Figure 3. PICA availability risk matrix[10-8]

Sustaining Game Changing TPS for Extreme Entry Environments: HEEET. HEEET is a highly capable TPS for the most severe entry environments; it recently achieved TRL 6 for representative Venus and Outer Planet direct entry missions [9]. This achievement was the result of significant investment by NASA's Space Technology and Science Mission Directorates over more than 6 years. The HEEET system replaces capability once provided by Heritage Carbon Phenolic. HEEET's dual layer design (Figure 4) is more mass efficient than HCP for missions that use high speed entry 
to deliver landers, probes, aerial platforms, and skimmers. The investment in HEEET followed two workshops held by NASA Ames in 2010-11 examining technology atrophy and supply chain challenges for the heritage carbon phenolic used in Pioneer-Venus and Galileo missions [10]. These workshops looked at the development work needed to restart HCP by qualifying a new rayon-based carbon fiber and revive the chop-molded carbon phenolic process (CMCP). The CMCP nose cap technology restoration was perceived as particularly challenging since it had not been produced nor flown since the 1970s-80s, when Pioneer-Venus spent considerable effort developing the technology. The NASA TPS community deemed the redevelopment of HCP to be unsustainable and ineffective [11]. The workshops also looked at alternative technologies that had the potential to be more sustainable, including 3D Woven TPS that later spawned HEEET.
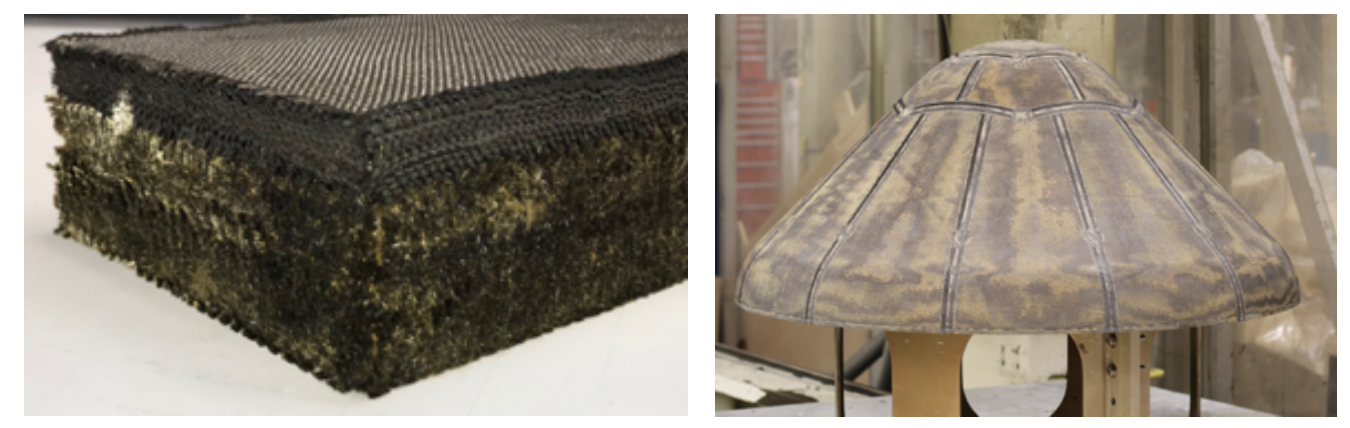

Figure 4. HEEET's 3D woven dual layer construction (left) makes it a robust and efficient TPS; HEEET 1-meter diameter engineering test unit with integrated seams (right)

Unfortunately, there are no current missions that require the dual-layered, tiled HEEET system, and there is no foreseeable infusion pathway before approximately 2030. While MSR is pursuing a single-layer, seamless derivative of HEEET, fabrication of this system would not maintain the unique weaving capability developed by Bally Ribbon Mills in partnership with NASA for the dual-layered HEEET. Furthermore, the HEEET insulating layer is woven from a hybrid carbon/phenolic yarn produced via a proprietary process from a single vendor. NASA's search for comparable processing by other vendors has revealed meaningful differences in this key ingredient for HEEET, and thus the sole source vendor is considered crucial for maintaining HEEET as currently qualified. The considerable expertise developed by NASA to design, build, and particularly to integrate the tiles and seams of the HEEET engineering test unit is one of NASA's crucial capabilities for sustaining this technology at TRL 6. While the HEEET Design Data Book does an excellent job of documenting the many processes and lessons learned for this process, it cannot replace the expertise of the technologists who created it.

\section{HEEET Risk Assessment}

- Since no current missions require the dual-layered, tiled HEEET system before 2030 significant loss of expertise and atrophy of production and integration capabilities would be expected in the absence of use.

- The HEEET vendor developed a highly specialized process for blending the insulating layer yarn from carbon and phenolic fibers, and loss of this capability/vendor is a sustainability risk in the absence of use. 
- HEEET gap filler design and integration is complex; while documentation is established, lack of practicing the procedures with experienced personnel will increase risk of process recovery for future missions

- HEEET development established a unique weaving process and loom, and this capability is at risk in the absence of use.

- The NASA ARC Entry Systems and Technology Division has documented detailed HEEET fabrication sustainability risks [12], and an associated risk matrix is shown in Figure 5.

\section{Proposed HEEET Sustainability Risk Mitigations}

- NASA should perform annual assessments of future HEEET demand, starting material availability, processing equipment and integration procedure/personnel readiness

- Annual assessments should be conducted to determine whether technology atrophy risk has changed, and the HEEET Sustainability Assessment document [12] should be updated based on this information.

- If the risk becomes high, NASA ARC should bring a funding proposal forward to HQ to mitigate the risk through manufacturing, integration or other means.

- NASA should ensure weaving, resin infusion, tile/seam integration and TPS performance are maintained by funding periodic (few to several years) small-scale HEEET material production, article fabrication and testing plus small-scale integrated tile/seam unit build.

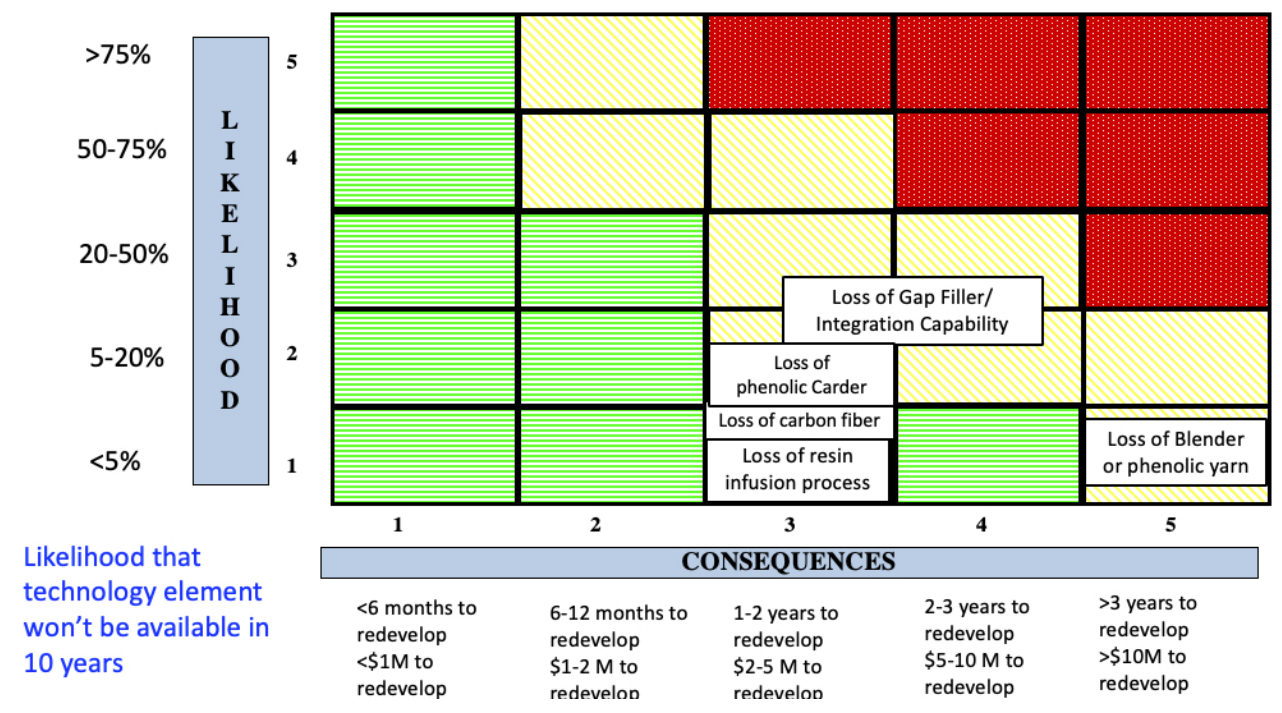

Figure 5. HEEET Availability Risk Matrix [12]

Conclusion: NASA-invented TPS, specifically PICA and HEEET, are critical for future Venus and outer planet in-situ missions deploying landers, probes, aerial platforms, and skimmers. These technologies are uniquely used by NASA and will not be sustained in the absence of use. Key sustainability concerns include highly specialized expertise shared between NASA and industry, raw material and TPS manufacturing supply chains, and system integration. Given that long periods of production inactivity are anticipated for these technologies, a method for monitoring and potentially mitigating sustainability risk is proposed herein. The approach entails 
Sustaining Mature Thermal Protection Systems Crucial for Future In-Situ Planetary Missions

establishing configuration controlled TPS risk assessment documents for PICA and HEEET that are updated on an annual basis by NASA ARC, followed by feedback to SMD leadership on risk assessment as well as a mitigation proposal, with cost and schedule, if the risk is sufficiently high. Currently, the risk of high cost or long duration redevelopment for PICA or HEEET required to support the next decade's priority planetary entry missions is assessed in the low to moderate range as shown in Figures 3 and 5. An assessment of high risk would trigger engagement of SMDPSD.

\section{References:}

1. Venus Technology Plan, 2019, Venus Exploration and Analysis Group.

2. E. Venkatapathy, J. Reuther, "NASA Crew Exploration Vehicle, Thermal Protection System, Lessons Learned," presented at the $6^{\text {th }}$ International Planetary Probe Workshop, Atlanta, Georgia, June $26^{\text {th }}, 2008$.

3. D. Ellerby, E. Venkatapathy, M. Stackpoole, R. Chinnapongse, J. Feldman, D. Prabhu, A. Beerman, "Woven Thermal Protection System Based Heatshield for Extreme Entry Environments Technology (HEEET)," presented at National Space and Missile Materials Symposium, Bellevue, WA, June 24-27, 2013.

4. Venkatapathy, E., Ellerby, E., Gage, P., et al., "Entry System Technology Readiness for IceGiant Probe Missions." Space Science Reviews, 216, no. 2 (2020): 1-21.

5. E. Venkatapathy, "Ablators - From Apollo to Future Missions to Moon, Mars and Beyond," presented at the $70^{\text {th }}$ International Astronautical Congress (IAC), Washington D.C., United States, 21-25 October 2019, IAC Paper \# IAC-19,C2,4,1,x55164

6. H. Tran, W. Henline, M. Hsu, D. Rasky, S. Riccitiello, "Low-Density Resin Impregnated Ceramic Article Having an Average Density of 0.15 to $0.40 \mathrm{~g} / \mathrm{cc}$," US Patent no. 5,536,562, July 16, 1996.

7. D. Kontinos, M. Wright, "Introduction: Atmospheric Entry of the Stardust Sample Return Capsule," Journal of Spacecraft and Rockets, Vol. 47, No. 5, Sep.-Oct. 2010, pp. 705-707.

8. NASA ARC configuration managed document for PICA manufacturing sustainability risk assessment, designation pending.

9. D. Ellerby, M. Gasch, "Heatshield for Extreme Entry Environment Technology (HEEET) Thermal Protection System (TPS)", presented at Materials Science and Technology (MS\&T), Portland, OR, Sep. 29 - Oct. 3, 2019.

10. J. Feldman, J. Arnold, "Current Capabilities, Gaps and Development Pathways Required to Enable Future Planetary Missions that need Carbon Phenolic Heatshields: Mars Sample Return, Venus and the Outer Planets; Summary Report to NASA's Office of the Chief Engineer and Office of the Chief Technologist ISPT Program Office SMD," July 26, 2010.

11. N. Cheatwood, D. Ellerby, J. Feldman, M. Gasch, A. Morris, M. Munk, E. Venkatapathy, M. Wright, "Carbon Phenolic \& Beyond Workshop: Summary Report to NASA's Office of the Chief Technologist, Office of the Chief Engineer, and Science Mission Directorate," April 2012.

12. NASA ARC configuration managed document for HEEET manufacturing sustainability risk assessment, designation pending. 